Original article

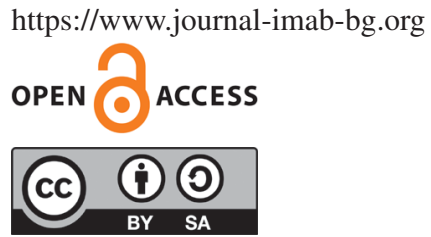

\title{
MEDICAL EVALUATION OF THE POTENTIAL BIOLOGICAL AND CHEMICAL DANGERS IN HIGH-RISK FOODS
}

\author{
Tsvetelina G. Vitkova, Rositsa K. Enikova, Mariyana R. Stoynovska, \\ Department of Hygiene, medical ecology, occupational diseases and disaster \\ medicine, Faculty of Public Health, Medical University, Pleven, Bulgaria.
}

\section{SUMMARY}

Purpose: The current European legislation assigned the responsibility for food safety to the food producers and traders. In this aspect, the aim of the survey was to provide critical analysis of the functioning of Hazard Analysis and Critical Control Point (HACCP) systems in the production of foods, presenting certain risks of specific public health hazards - foodborne toxicoinfections, infections and intoxications, for chemical contamination and additives, etc.

The survey covered HACCP-systems and prerequisite programmes of 4 enterprises manufacturing confectionery products, ready-to-serve foods, pasteurized egg products, sterilized canned foods.

Material/methods: Monitoring and critical analysis of the In-plant control system and HACCP of four enterprises for the production of: confectionery products, ready-to-serve-dishes in public catering, sterilized canned foods, pasteurized egg semi-ready products

Results: The current experience has revealed major defects in hazard analysis, adequacy of critical points, corrective actions and verification procedures. The article contains recommendations and suggestions for improving the work of manufacturers and harmonizing relationships with regulatory authorities in the event of inconsistencies in production.

Conclusions: The authors concluded that a comprehensive medical evaluation of the HACCP systems was necessary for the prevention of foodborne diseases.

Keywords: Food safety, Confectionery products, Ready-to-serve dishes, Sterilized canned foods, Pasteurized egg products,

\section{INTRODUCTION}

Due to the enormous international interest in food safety, there has been a need to examine how the needs of society, the environment and health prevention have been addressed. This interest emphasizes whether society is sufficiently aware of the criteria by which the food chain and food production, in particular those at high risk to consumer health, are assessed and monitored. The main purpose of the application of HACCP in all enterprises where food is produced and/or offered to humans is to minimize the possibility of an outbreak of food poisoning, as well as to protect the consumer from chemical contaminants, additives, mycotoxins and other potentially hazardous substances. [1, $2,3,4,5,6,7]$. This systematic preventive-medical activity and the associated responsibilities are totally assigned to food business operators.

The aim of the study is a medical analysis of the production of high-risk food products and the HACCP systems currently in place.

Part of our reasoning for this study is to formulate these understandings and emphases and put them at the heart of the modern validation of the principles of production in order to release safe foods on the market.

\section{MATERIAL AND METHODS}

Monitoring and critical analysis of the In-plant control system and HACCP of four enterprises for the production of:

- Confectionery products;

- Ready-to-serve-dishes in public catering;

- Sterilized canned foods;

- Pasteurized egg semi-ready products. [4].

\section{RESULTS}

The analysis and health assessment of the food safety management systems and the available documentation in the production of different food risk groups showed the following results:

1. Confectionery products - The analysis covered confectionery products with high water content, such as pastry, cakes, rolls etc. On pastries basis garnished with glazes, couverture, milk containing ones, chocolate, cream and buttercreams. Stored food is kept in the refrigerator. Shelf life from 5 to 8 days. This carries a scientifically proven risk of foodborne illness, mainly salmonella and staphylococcal food poisoning. [8, 9]. (Fig. 1). 
Fig. 1. The HACCP scope for confectionery products in the food chain

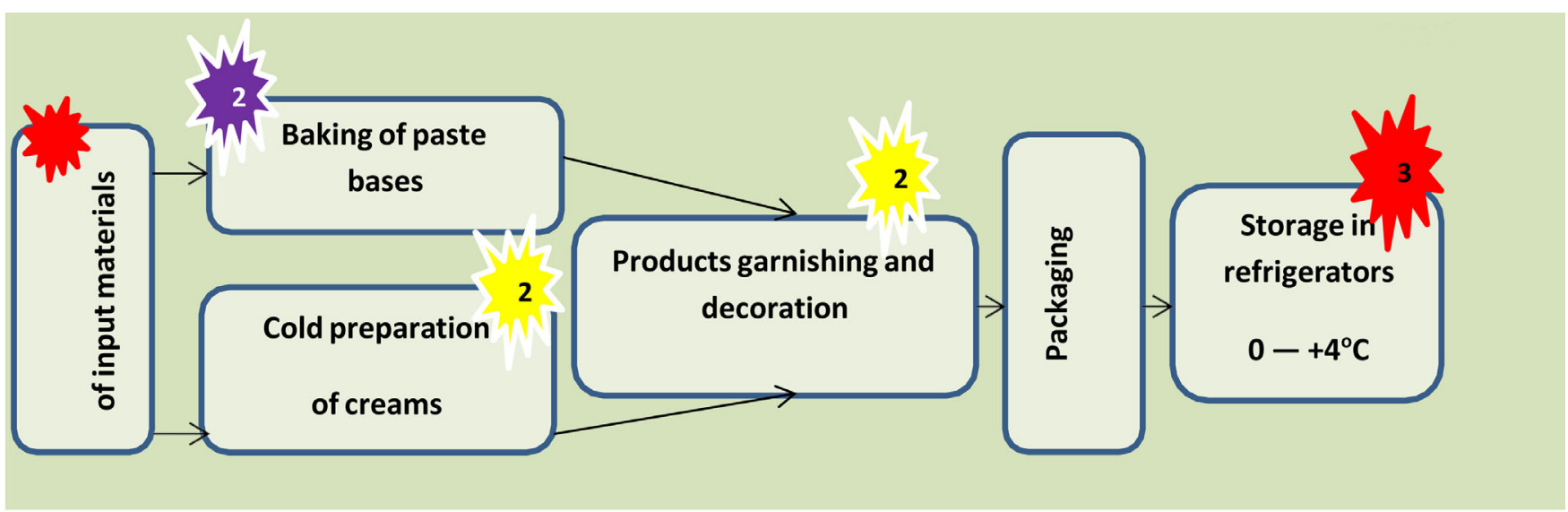

\begin{tabular}{|l|l|l|l|}
\hline & $\begin{array}{l}\text { Correctly identified critical control } \\
\text { point }\end{array}$ & $\begin{array}{l}\text { Incorrectly identified critical } \\
\text { control point }\end{array}$ \\
\hline 3 & Control point & $\begin{array}{l}\text { Additional critical control } \\
\text { point identified by the } \\
\text { analysis }\end{array}$ \\
\hline
\end{tabular}

CCP 1 (CCP - Critical Control Point) and CCP 3 are identified correctly - in the first case, it is the place of prevention of physical hazards and in the second - prevention of the reproduction of unwanted flora of the ready product (Table 1).

Table 1. For ready confectionery products in CCP 3.

\begin{tabular}{|c|c|c|c|c|c|}
\hline \multirow{2}{*}{ Criteria } & \multicolumn{4}{|c|}{ Limits } & \multirow{2}{*}{ Periodicity } \\
\hline & $n^{* *}$ & $c^{* * *}$ & $\mathbf{m} * * * *$ & $\mathbf{M} * * * * *$ & \\
\hline Coliforms, CFU*/g & 5 & 2 & 10 & 100 & Monthly \\
\hline $\begin{array}{l}\text { Coagulase-positive staphylococci, } \\
\text { CFU/g }\end{array}$ & 5 & 2 & 10 & 100 & Each trimester \\
\hline Salmonella spp. & 5 & $\mathbf{0}$ & \multicolumn{2}{|c|}{ Not present in $25 \mathrm{~g}$} & Once per 6 months \\
\hline
\end{tabular}

* CFU - colony-forming unit; $* * n$ - number of units in the sample; ***c-number of units above certain limits; $* * * * m-$ limits; $* * * * * M-$ limits.

- The place of CCP 2 is not at the thermal processing of the bases but in the part of the chain containing the manual operations - garnishing and decoration of the products and cold preparation of the creams. Secondary contamination with unwanted microorganisms is possible (Table 2).

Table 2. Microbiological samples taken from the equipment, environment and staff responsible for garnishing and decorating that is done in direct contact with the confectionery products in CCP 2.

\begin{tabular}{|c|c|c|c|}
\hline Sample type & Microbiological criteria & Limits & Periodicity \\
\hline Working surfaces and equipment & Coliforms & Not admitted & Monthly \\
\hline \multirow{2}{*}{ Staff hands } & Coliforms & Not admitted & \multirow{2}{*}{ Once per 2 months } \\
\hline & Coagulase-positive staphylococci & Not admitted & \\
\hline Working clothes & Coliforms & Not admitted & Once per 2 months \\
\hline $\begin{array}{l}\text { Upper respiratory tract } \\
\text { (nose, throat) }\end{array}$ & Coagulase-positive staphylococci & Not admitted & Once per 6 months \\
\hline
\end{tabular}


2. Ready-to-serve dishes - There are two omissions in the technical documents and in HACCP as well. [8, 9, 10].

- The temperature at which the dishes are stored warm before the consumption is not set (Fig. 2).

Fig. 2. The HACCP and outlined CP for these ready-to-serve meals.

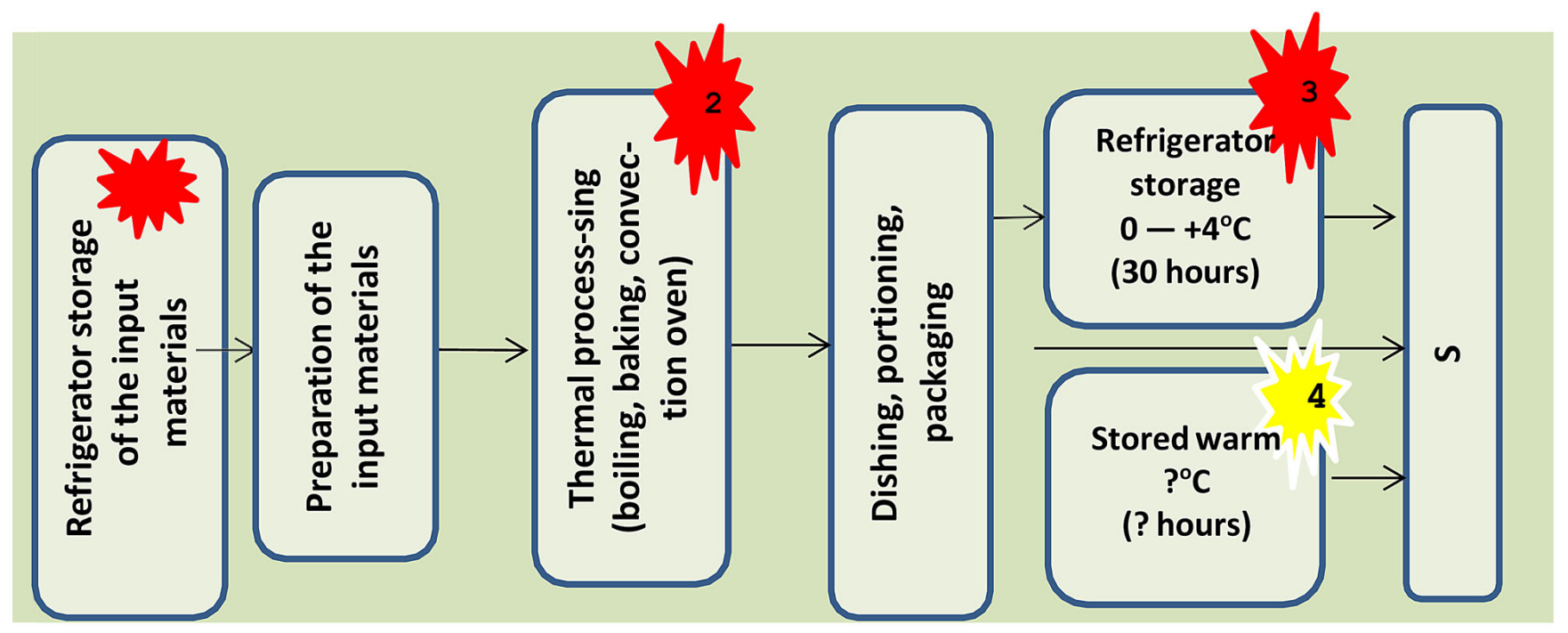

- The other omission is the lack of adequate microbiological requirements for ready-to-serve production (Table 3 ).

Table 3. Ready-to-serve meals (soups, cooked dishes, baked products) at CCP 3.

\begin{tabular}{|c|c|c|c|c|c|}
\hline \multirow{2}{*}{ Criteria } & \multicolumn{4}{|c|}{ Limits } & \multirow{2}{*}{ Periodicity } \\
\hline & $n^{* *}$ & $c^{* * *}$ & $\mathbf{m}^{* * * *}$ & $\boldsymbol{M} * * * * *$ & \\
\hline Escherichia coli, CFU*/g & 5 & 2 & 10 & 100 & Monthly \\
\hline Bacillus cereus, $\mathrm{CFU} / \mathrm{g}$ & 5 & 2 & 10 & 100 & Once per 3 months \\
\hline Sulfite reducing clostridia, $\mathrm{CFU} / \mathrm{g}$ & 5 & 2 & 10 & 100 & Once per 6 months \\
\hline Listeria monocytogenes & 5 & $\mathbf{0}$ & \multicolumn{2}{|c|}{ Not present in $25 \mathrm{~g}$} & Once per 6 months \\
\hline Salmonella spp. & 5 & 0 & \multicolumn{2}{|c|}{ Not present in $25 \mathrm{~g}$} & Once per 6 months \\
\hline
\end{tabular}

* CFU - colony-forming unit; $* *_{n}$ - number of units in the sample; $* * * c$ - number of units above certain limits; $* * * * m-$ limits; $* * * * * M-$ limits.

3. Sterilized canned foods - There is overwhelming scientific evidence for a major biological risk in the manufacture of sterilized cans. They are anaerobic non-spore-forming bacteria, especially Clostridium botulinum. This helps to clearly define the main CCP - sterilization. The products considered and analyzed by us are sterilized multicomponent canned vegetables. [11, 12].

- The HACCP team used a "decision tree" to identify three CPs (CP - Critical Point) and one CCP. (Fig. 3). 
Fig. 3. HACCP scope in the food chain (Sterilizes green peas).

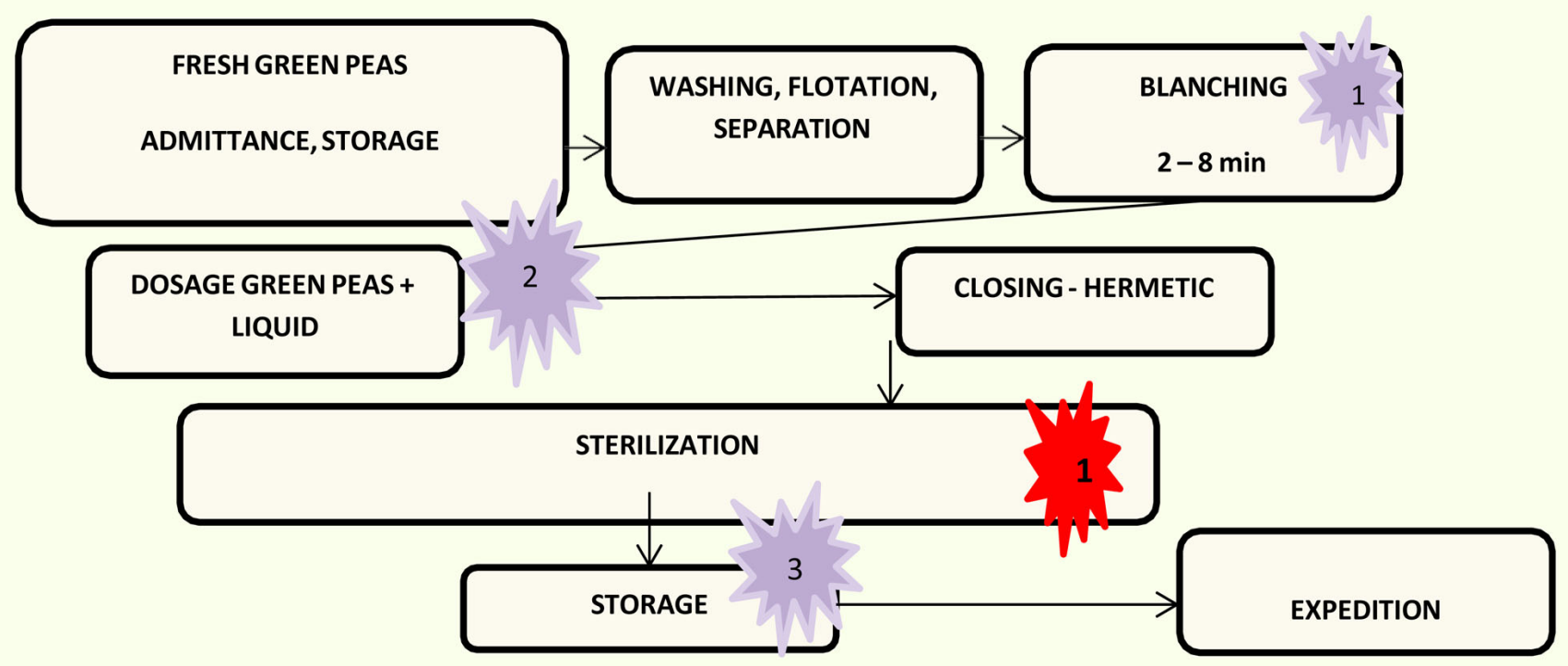

- The real assessment is given by the microbiological control of industrial sterility, which lies on in the basis of the recommended verification procedures. A check of CCP 1 (sterilization):

\section{Once per month:}

- Mesophilic aerobic and facultative anaerobic microorganisms - non spore forming and vegetative forms of spore forming ones;

- Spores of mesophilic aerobic and facultative anaerobic microorganisms;

- Mesophilic anaerobic microorganisms;

- Molds and yeasts.

Once every three months: spore forms.
4. Pasteurized egg products - Egg melange, egg yolk and egg white are produced here. These are semi-finished products that are used mainly in the production of confectionery goods at catering establishments, bakeries, etc. These semi-finished products hide the risk of biological contamination - salmonella, listeria, etc. $[13,14]$.

- Heat treatment is used to remove bacterial contamination of the raw egg mass. It is in the low pasteurization range of $57^{\circ} \mathrm{C}$ to $67^{\circ} \mathrm{C}$ at a flow rate of 1500 to $30001 / \mathrm{h}$.

- Scientifically based and correctly determined Ñ̃̃円 during production. A study of the documentation revealed one major drawback - an inconclusive check of pasteurization and storage (Fig. 4).

Fig. 4. The Technological process and CCP for pasteurized egg products

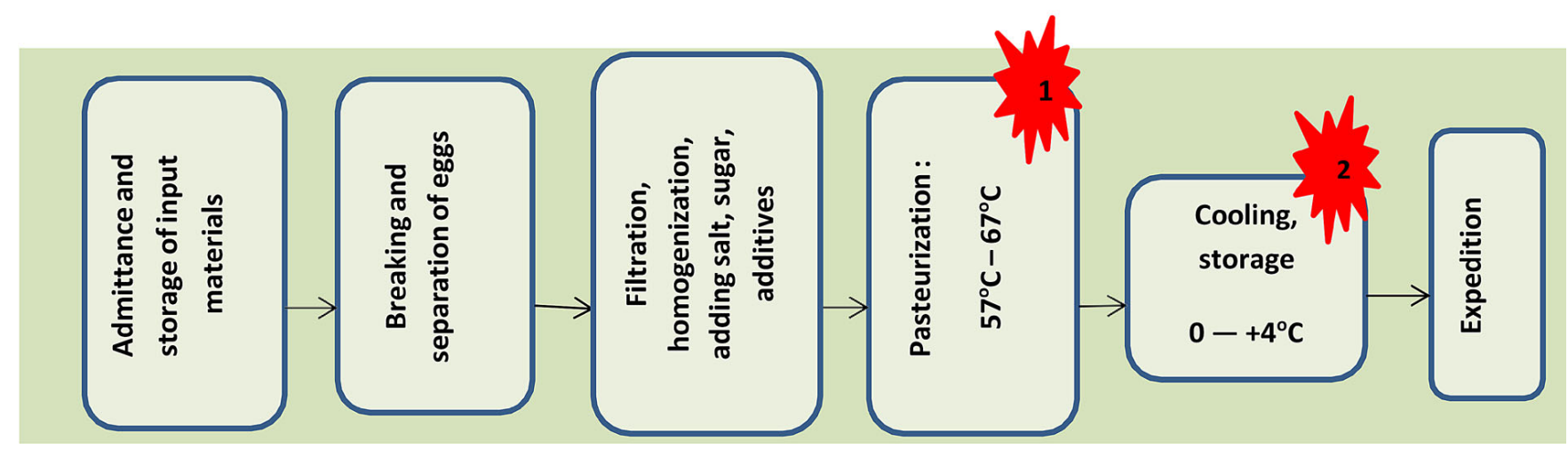


- The results and proposals from our finding were presented to the business operators. Verification tests in HACCP for pasteurized egg products at CCP 2:

\section{Once every three months:}

- Total count of mesophilic aerobic and facultative anaerobic microorganisms - $<50000 \mathrm{cfu} * / \mathrm{g}$;

- Enterobacteriaceae - $<10 \mathrm{cfu} / \mathrm{g}$;

- Molds and yeasts - <10 cfu/g;

- Salmonella spp. - $\mathrm{n}^{* *}=5 ; \mathrm{c} * * *=0 ; \mathrm{m} * * * *-$ absence in $25,0 \mathrm{~g}$ of the product.

* $C F U$ - colony-forming unit;

$* * n$ - number of units in the sample;

$* * * c$ - number of units above certain limits; $* * * * \mathrm{~m}-$ limits.

\section{DISCUSSION}

In the case of the confectionary products after the manual operations, there is practically no factor to eliminate or reduce to a safe level the introduction of microflora, and as a result of the analysis, we propose to place CCP 2 in the manual operations in the baking to remain only as $\mathrm{CP}$.

As far as ready-to-serve dishes are concerned, the temperature at which the dishes are stored should be not lower than $65^{\circ} \mathrm{C}$. Lower temperatures, such as $30^{\circ} \mathrm{C}-45$ ${ }^{\circ} \mathrm{C}$, would play the role of a thermostat for mesophilic and thermophilic microorganisms, place to reproduce and accumulate high infectious doses. This is the main cause of foodborne disease outbreaks in food service establishments, especially food service establishments. The definition of CCP 4 at this stage is required (Fig. 2). On the other hand, the criteria for the three types of food production are minimal and do not take into account real hazards. Based on the results of the analysis, we recommend the following microbiological criteria for the safety and hygiene of processes on the basis of which control and verification should be carried out (Table 3 ).

Sterilized can foods processes have little to no improvement improve to make due to the clear vision and outline of the process of sterilization, which eliminates the risk of the dominating biohazards.

In the case of pasteurized egg products, the existing risk of microbial contamination must be taken into account.
The heat treatment that is carried out preserves their properties and prevents protein denaturation but does not guarantee the absence of epidemiological risk. With this in mind, after analysis, we propose appropriate checks corresponding to the degree of risk (Fig. 4). At the production sites analyzed by us, potential chemical contaminants are regulated through the incoming control of the received materials, which are possible carriers. The proposed checks and procedures for controlling the risks at the sites, as well as the documentation reviews performed, are provided to the HACCP teams to optimize risk management.

\section{CONCLUSIONS}

The analyzed production sites and the products manufactured there are classified as high risk. Produced food is a potential source of bacterial contamination and poses a potential health risk to consumers.

The food safety management systems developed by the teams comply with the requirements of European and national legislation.

Biological hazards are dominant in four types of production. They can be caused by primary or secondary contamination and can be a potential cause of undesirable consequences in terms of both the quality and safety of the finished product.

A drawback in the development of HACCP is the misidentification of $\mathrm{CP}$ and $\mathrm{CCP}$ as a result of underestimation of biological hazards.

The weak point of the presented food safety management systems is the insufficiently reliable system for checking the effectiveness of the processes.

The application of HACCP systems, especially for foods with a high potential risk of bacterial foodborne diseases, requires consultation with a healthcare professional. A medical hazard assessment in industrially produced food is mandatory.
Abbreviations
HACCP - Hazard Analysis and Critical Control Point
CCP - Critical Control Point
CP - Critical Point
CFU - colony-forming unit

\section{REFERENCES:}

1. 2016/C 278/01. Commission Notice on the implementation of food safety management systems covering prerequisite programs (PRPs) and procedures based on the HACCP principles, including the facilitation/flexibility of the implementation in certain food businesses. EU. 30 July 2016. [nternet]

2. Dineva S. [Major contaminants in food raw materials and products.] [in Bulgarian] Tracia University Stara Zagora. 2016. 156 p.
3. ISO 22000: 2018. Food safety management systems - Requirements for any organization in the food chain. [Internet]

4. Food quality and safety systems. A training manual on food hygiene and the Hazard Analysis and Critical Control Point (HACCP) system. FAO. 1998. [Internet]

5. Regulation (EC) No 853/2004 of the European Parliament and of the Council of 29 April 2004 laying down specific hygiene rules for food of ani- mal origin. OJ L139, 30. 4. 2004. EU. [Internet]

6. Requirements for a haccp based food safety system. Option A: Management System Certification. Compiled by the National Board of Experts HACCP The Netherlands. Gorinchem, the Netherlands: 4th Version. June, 2006. 48 p.

7. Enikova R, Stoynovska M, Karcheva M. Mycotoxins in Fruits and Vegetables. J of IMAB. 2020 Apr-Jun; 26(2):3139-3143. [Crossref] 
8. Encyclopedia of food safety. First edition. Edited by Motarjemi Y, Moy G, Todd E. Academic Press. 12th December 2013. 2304 p. [ㅍternet]

9. Microbial Food Safety. An Introduction. Editors: Oyarzabal OA, Backert S. Springer-Verlag New York. 2012. [Crossref]

10. Guidelines for Assessing the Microbiological Safety of Ready-toEat Foods Placed on the Market. London: Public Health England. Novem- ber 2009. 34 p. [ Internet]

11. National Enteric Disease Surveillance: Botulism Surveillance Overview. CDC. March 2012. 3 p. [Internet]

12. Hersum A, Holland E. [Canned foods. Thermal sterilization and microbiology.] [in Russian] Publishing House Legkaya I pishtevaya promishlenost. 1983. 319 p.

13. Enikova R, Baklova I, Kozareva M, Ribarova F, Petrova S,
Peshevska M, et al. [Medicobiological characteristics of dry egg mélange produced in the People's Republic of Bulgaria.] [in Bulgarian]. Food industry science. 1986. No. 6. 25-33.

14. Guide to good manufacturing practice for "Liquid, concentrated, frozen and dried egg products" used as food ingredients (non-ready to eat egg products). EEPA. Mar 2011. 40 p. [Internet]

Please cite this article as: Vitkova TG, Enikova RK, Stoynovska MR. Medical evaluation of the potential biological and chemical dangers in high-risk foods. J of IMAB. 2021 Jul-Sep;27(3):3924-3929.

DOI: https://doi.org/10.5272/jimab.2021273.3924

Received: 10/05/2021; Published online: 07/09/2021

\section{Address for correspondence:}

Tsvetelina G. Vitkova

Department of Hygiene, Medical Ecology, Occupational Diseases and MBS, Faculty of Public Health, Medical University - Pleven,

1, K1. Ohridski str., Pleven, 5800, Bulgaria

E-mail: cvetelinavit@abv.bg 